OPEN ACCESS

Edited by:

Min Yue,

Zhejiang University, China

Reviewed by:

Laura Nicoleta Burga,

University of Otago, New Zealand

Alexey V. Rakov,

Somov Institute of Epidemiology and

Microbiology, Russia

*Correspondence:

Shao-Lun Zhai

zhaishaolun@163.com orcid.org/0000-0003-3217-2256

Ming Liao

mliao@scau.edu.cn

Dong-Sheng $\mathrm{He}$

dhe@scau.edu.cn

tThese authors have contributed equally to this work

Specialty section:

This article was submitted to Veterinary Infectious Diseases,

a section of the journal

Frontiers in Veterinary Science

Received: 25 June 2021 Accepted: 20 September 2021

Published: 25 October 2021

Citation:

Zhou X, Liang W-F, Si G-B, Li J-H, Chen Z-F, Cai W-Y, Lv D-H, Wen X-H, Zhai $Q$, Zhai S-L, Liao $M$ and He D-S (2021) Buffalo-Origin Seneca Valley Virus in China: First Report, Isolation,

Genome Characterization, and Evolution Analysis.

Front. Vet. Sci. 8:730701

doi: 10.3389/fvets.2021.730701

\section{Buffalo-Origin Seneca Valley Virus in China: First Report, Isolation, Genome Characterization, and Evolution Analysis}

\author{
Xia Zhou ${ }^{1,2,3+}$, Wei-Fang Liang ${ }^{1+}$, Guang-Bin Si ${ }^{1}$, Jin-Hui Li ${ }^{1}$, Zhi-Fei Chen ${ }^{1}$, Wei-You Cai ${ }^{1}$, \\ Dian-Hong Lv ${ }^{2,3}$, Xiao-Hui Wen ${ }^{2,3}$, Qi Zhai ${ }^{2,3}$, Shao-Lun Zhai ${ }^{2,3 *}$, Ming Liao ${ }^{2,3 *}$ and \\ Dong-Sheng $\mathrm{He}^{1 *}$ \\ ${ }^{1}$ College of Veterinary Medicine, South China Agricultural University, Guangzhou, China, ${ }^{2}$ Institute of Animal Health, \\ Guangdong Academy of Agricultural Sciences, Scientific Observation and Experiment Station of Veterinary Drugs and \\ Diagnostic Techniques of Guangdong Province, Ministry of Agriculture of Rural Affairs, Guangzhou, China, ${ }^{3}$ Key Laboratory \\ of Animal Disease Prevention of Guangdong Province, Guangzhou, China
}

Pigs are the main host of Seneca Valley virus (SW), previously known as Senecavirus A (SVA). Pigs affected by SW have vesicles in the nose, hooves, and limp and may cause death in some severe cases. Occasionally, SW has also been detected in mice, houseflies, environmental equipment, and corridors in pig farms. Moreover, it was successfully isolated from mouse tissue samples. In this study, an SW strain (SVA/GD/China/2018) was isolated from a buffalo with mouth ulcers in the Guangdong province of China using seven mammalian cell lines (including BHK-21, NA, PK-15, ST, Vero, Marc-145, and MDBK). The genome of SVA/GD/China/2018 consists of 7,276 nucleotides. Multiple-sequence alignment showed that SVA/GD/China/2018 shared the highest nucleotide similarity (99.1\%) with one wild boar-origin SW strain (Sichuan HS-01) from the Sichuan province of China. Genetic analysis revealed that SVA/GD/China/2018 clustered with those porcine-origin SW strains. To the best of our knowledge, this is the first report of SW infection in buffalo, which might expand the host range of the virus. Surveillance should be expanded, and clinical significance of SW needs to be further evaluated in cattle.

\section{Keywords: Seneca Valley virus, porcine, buffalo, first report, cell lines, host diversity}

\section{INTRODUCTION}

Seneca Valley virus (SVV), previously named Senecavirus A (SVA), is the only member of the Senecavirus genus in the Picornaviridae family. A typical SVV genome structure is L-VP4-VP2VP3-VP1-2A-2B-2C-3A-3B-3C-3D. Both the $5^{\prime}$ and $3^{\prime}$ ends are untranslated regions (UTRs) (1). Pigs infected with SVV primarily present with vesicular rash on the nose and coronary band vesicles (2). In severe cases, limping and death occur due to acute myocarditis, heart degeneration, transient fever, and neurological pathology (3). Although SVV was detected in samples as early as 1988 (4), it did not cause any obvious clinical symptoms in pigs before 2008. Sporadic outbreaks of obviously pathogenic SVV occurred between 2008 and 2014. Since 2015, large-scale outbreaks have appeared in the United States, Canada, Brazil, China, Thailand, and Vietnam (2-5). SVV has been detected in mice, houseflies, environmental equipment, and corridors in pig farms and was successfully 
isolated from mouse tissue samples (6). However, there are no reports of SVV in buffalo. In this study, one SVV strain was first isolated from a buffalo farm in Guangdong, China. The virus was successfully cultured in BHK-21 and NA cells (mouseorigin), PK-15 and ST cells (pig-origin), Vero and Marc-145 cells (monkey-origin), and MDBK cells (bovine-origin). In addition, the viral genome was sequenced and characterized.

\section{MATERIALS AND METHODS}

\section{Sample Information}

In October 2018, foot and mouth disease (FMD)-like clinical signs, including fever, hoof decay, and limping, were observed in three buffaloes from a buffalo farm $(n=80)$ in Guangdong, China. Three oral swabs were collected by the farm owner and transported to the Animal Disease Diagnostic Center, Institute of Animal Health, Guangdong Academy of Agricultural Sciences, using an insulated container with an ice pack.

\section{Detection of Potential Pathogens}

The viral DNA/RNAs were extracted from the oral swab fluids with the AxyPrep Body Fluid Viral DNA/RNA Miniprep Kit (Corning Life Sciences Co., Ltd., Wujiang, China) and used for reverse transcription PCR to detect foot-and-mouth disease virus (FMDV) (Shenzhen Aodong Inspection and Testing Technology Co., Ltd., Shenzhen, China), vesicular stomatitis virus (VSV) (Guangzhou Vipotion Biotechnology Co., Ltd., Guangzhou, China), bovine viral diarrhea virus (BVDV), bluetongue virus (BTV), and bovine alpha herpesvirus 1 (BoHV-1) according to the reference protocols (7). SVV was also detected using primers SVV-JCF (5'-ATGGTTGGTTTAGCCTGCACAAG-3') and SVV-JCR (5'-AAGCACGGATGAGACAGAGTTCCAA-3'). One-step RT-PCR (TaKaRa One Step PrimeScript ${ }^{\text {TM }}$ RT-PCR Kit, Otsu, Shiga, Japan) was performed with a final reaction volume of $25 \mu \mathrm{l}$, containing $12.5 \mu \mathrm{l} 2 \times 1$ step buffer (Takara,
Inc., Shiga, Japan), $0.5 \mu$ l PrimeScript One-Step Enzyme Mix (including reverse transcriptase and DNA polymerase), $3 \mu \mathrm{l}$ viral RNA, $0.5 \mu \mathrm{l}$ of each primer $(10 \mu \mathrm{mol} / \mathrm{l})$, and $8 \mu \mathrm{l}$ RNasefree $\mathrm{ddH}_{2} \mathrm{O}$. PCR conditions were as follows: $50^{\circ} \mathrm{C}$ for $30 \mathrm{~min}$, $94^{\circ} \mathrm{C}$ for $5 \mathrm{~min}$ followed by 35 cycles of $94^{\circ} \mathrm{C}$ for $30 \mathrm{~s}, 59^{\circ} \mathrm{C}$ for $30 \mathrm{~s}$, and $72^{\circ} \mathrm{C}$ for $30 \mathrm{~s}$, then the final extension step was $72^{\circ} \mathrm{C}$ for $5 \mathrm{~min}$. The PCR products were purified with an agarose gel DNA extraction kit (Takara Biomedical Technology, Beijing, Co., Ltd.). The gene cloning experiments were conducted with TaKaRa pMD19-T Vector Cloning Kit (Otsu, Shiga, Japan) and E. coli $\mathrm{DH} 5 \alpha$ competent cells (Otsu, Shiga, Japan). In addition, the positive recombinant plasmids were obtained using AxyPrep Plasmid Miniprep Kit (Corning Life Sciences Co., Ltd., Wujiang, China) and sequenced by the Sanger sequencing method (Sangon Biotech Co., Ltd. Shanghai, China).

\section{The Isolation and Propagation of SVV}

Eight cell lines from four different origins were used for virus isolation, which were stored at College of Veterinary Medicine, South China Agricultural University, and Institute of Animal Health, Guangdong Academy of Agricultural Sciences. We used eight cell types of four different origins to isolate the virus. BHK-21 cells, PK-15 cells, ST cells, Vero cells, Marc-145 cells, MDCK cells, and MDBK cells were cultured and passaged in the following growth medium: Dulbecco's modified Eagle's medium (DMEM) (4.5 g/l D glucose, Gibco ${ }^{\mathrm{TM}}$, Grand Island, NY, USA). The NA cells were cultured using 1640 medium (RPMI, Gibco ${ }^{\mathrm{TM}}$, USA) supplemented with $10 \%(\mathrm{v} / \mathrm{v})$ fetal bovine serum (FBS, Gibco $^{\mathrm{TM}}$, South American). Before the virus inoculation, cell monolayers were washed three times with phosphate-buffered saline without $\mathrm{Mg}_{2+}$ and $\mathrm{Ca}_{2+}\left[\mathrm{PBS}^{(-/-)}\right]$to remove FBS and cell metabolites. The virus was added to the cells and incubated at $37^{\circ} \mathrm{C}$ with a $5 \% \mathrm{CO}_{2}$ incubator for $1 \mathrm{~h}$. After virus attachment, the virus inoculum was removed and the $\operatorname{PBS}^{(-/-)}$was also used to wash the cell monolayers three times again. Then, the maintenance medium (NA cells: 1640, RPMI, Gibco ${ }^{\mathrm{TM}}$, USA, other seven cells: DMEM, $4.5 \mathrm{~g} / 1 \mathrm{D}$ glucose, Gibco ${ }^{\mathrm{TM}}$,

TABLE 1 | Primers used for genome amplification of SW.

\begin{tabular}{|c|c|c|c|c|c|c|}
\hline Primer & Nucleotide sequence $\left(5^{\prime}-3^{\prime}\right)$ & $\begin{array}{l}\text { Denaturation } \\
\text { temperature }\end{array}$ & $\begin{array}{c}\text { Annealing } \\
\text { temperature }\end{array}$ & $\begin{array}{c}\text { Extension } \\
\text { temperature }\end{array}$ & $\begin{array}{c}\text { Extension } \\
\text { time }\end{array}$ & $\begin{array}{c}\text { Product } \\
\text { length (bp) }\end{array}$ \\
\hline SW 1-F & TाTGAAATGGGGGGCTGGGC & $95^{\circ} \mathrm{C}$ & $62^{\circ} \mathrm{C}$ & $72^{\circ} \mathrm{C}$ & $30 s$ & 482 bp \\
\hline SW 1-R & GTACTCATGGTGGTAGCAGTCACGTGG & & & & & \\
\hline SW 2-F & ATCACTGAACTGGAGCTCGA & $98^{\circ} \mathrm{C}$ & $57^{\circ} \mathrm{C}$ & $68^{\circ} \mathrm{C}$ & $90 \mathrm{~s}$ & $1,443 \mathrm{bp}$ \\
\hline SW 2-R & AGGAGTTCTGTGTCTCTGAGGA & & & & & \\
\hline SW 3-F & AGTCTCTTGGCACATACTATCGG & $98^{\circ} \mathrm{C}$ & $58^{\circ} \mathrm{C}$ & $68^{\circ} \mathrm{C}$ & $100 \mathrm{~s}$ & 1,614 bp \\
\hline SW 3-R & AAGCACGGATGAGACAGAGTTC & & & & & \\
\hline SW 4-F & TTAAGGTACTGGAGAAGGACGC & $98^{\circ} \mathrm{C}$ & $57^{\circ} \mathrm{C}$ & $68^{\circ} \mathrm{C}$ & $90 \mathrm{~s}$ & $1,385 \mathrm{bp}$ \\
\hline SW 4-R & TGGCATTGATCATAGTGGTGAG & & & & & \\
\hline SW 5-F & TTGGCTCATGATGCCTTCAT & $98^{\circ} \mathrm{C}$ & $56^{\circ} \mathrm{C}$ & $68^{\circ} \mathrm{C}$ & $90 \mathrm{~s}$ & $1,437 \mathrm{bp}$ \\
\hline SW 5-R & GTCCAAACTTGTCTAGATTGTTAGGG & & & & & \\
\hline SW 6-F & CAACAGACCTTCTGGACTTACAC & $98^{\circ} \mathrm{C}$ & $57^{\circ} \mathrm{C}$ & $68^{\circ} \mathrm{C}$ & $90 \mathrm{~s}$ & $1,505 \mathrm{bp}$ \\
\hline SW 6-R & AGAGCAGTCCTGATGATCACA & & & & & \\
\hline SW 7-F & CTCCTTCGAGGCTCTCATCT & $98^{\circ} \mathrm{C}$ & $58^{\circ} \mathrm{C}$ & $68^{\circ} \mathrm{C}$ & $35 s$ & 707 bp \\
\hline SW 7-R & TCTGTTCCGACTGAGTTCTCC & & & & & \\
\hline
\end{tabular}


USA) supplemented with $2 \%(\mathrm{v} / \mathrm{v})$ FBS was added to cells for propagation and passage. The cytopathic effects (CPE) were monitored daily until $>90 \%$ of the cells showed CPE. The cells were frozen and thawed for three times between $-80^{\circ} \mathrm{C}$ and room temperature, and the virus was filtered with a $0.22-\mu \mathrm{m}$ filter to remove cell debris and stored at $-80^{\circ} \mathrm{C}$ until further study. Then, the harvested virus solution was identified by RTPCR and subcultured. SVV was then purified by the virus plaque assay (8). The appropriate plaques were collected and diluted with an appropriate amount of phosphate-buffered saline $\left(\mathrm{PBS}, \mathrm{Gibco}^{\mathrm{TM}}\right)$. Plaques identified as positive by RT-PCR were inoculated into PK-15 cells and BHK-21 cells, and then passaged and recorded.

\section{Genome Amplification of SVV}

The SVV genome was amplified using seven pairs of primers (Table 1) from one of two positive oral swabs. The target fragments were amplified by the one-step TaKaRa kit (TaKaRa), and the reaction system was $50 \mu \mathrm{l}$, including $1 \mu \mathrm{l}$ PrimeScript One-Step Enzyme Mix, $25 \mu l 2 \times$ one-step buffer, $1 \mu l$ forward primer $(10 \mu \mathrm{mol} / \mathrm{l}), 1 \mu \mathrm{l}$ reverse primer $(10 \mu \mathrm{mol} / \mathrm{l}), 5 \mu \mathrm{l}$ RNA template, and $17 \mu \mathrm{l}$ RNase-free $\mathrm{ddH}_{2} \mathrm{O}$. Cycling conditions were as follows: $50^{\circ} \mathrm{C}$ for $30 \mathrm{~min}$, pre-denaturation temperature for $5 \mathrm{~min}$ followed by 40 cycles of denaturation temperature for $30 \mathrm{~s}$, annealing temperature for $30 \mathrm{~s}$ or $15 \mathrm{~s}$, and extension temperature for $30-100 \mathrm{~s}$, separately. A final extension condition was $10 \mathrm{~min}$ at 68 or $72^{\circ} \mathrm{C}$ (Table 1). The target fragments were purified and recovered by an agarose gel DNA extraction kit (TaKaRa). Then each of the seven amplicons of SVV was cloned into pMD19-T. The ligated vector pMD19-T (TaKaRa) was introduced into $E$. coli competent cell DH5 $\alpha$ (TaKaRa) for cloning. The extracted plasmids were sent to Sangon Biotech Co., Ltd. (Guangzhou Branch), for sequencing.

\section{Sequence Analysis of SVV}

We constructed a genetic evolutionary tree based on the SVV polyprotein gene with 1,000 bootstrap replicates using MEGA 6.06 software (neighbor-joining method). Full-length nucleotide and amino acid sequence alignments between SVA/GD/China/2018 and other 35 SVV strains published from

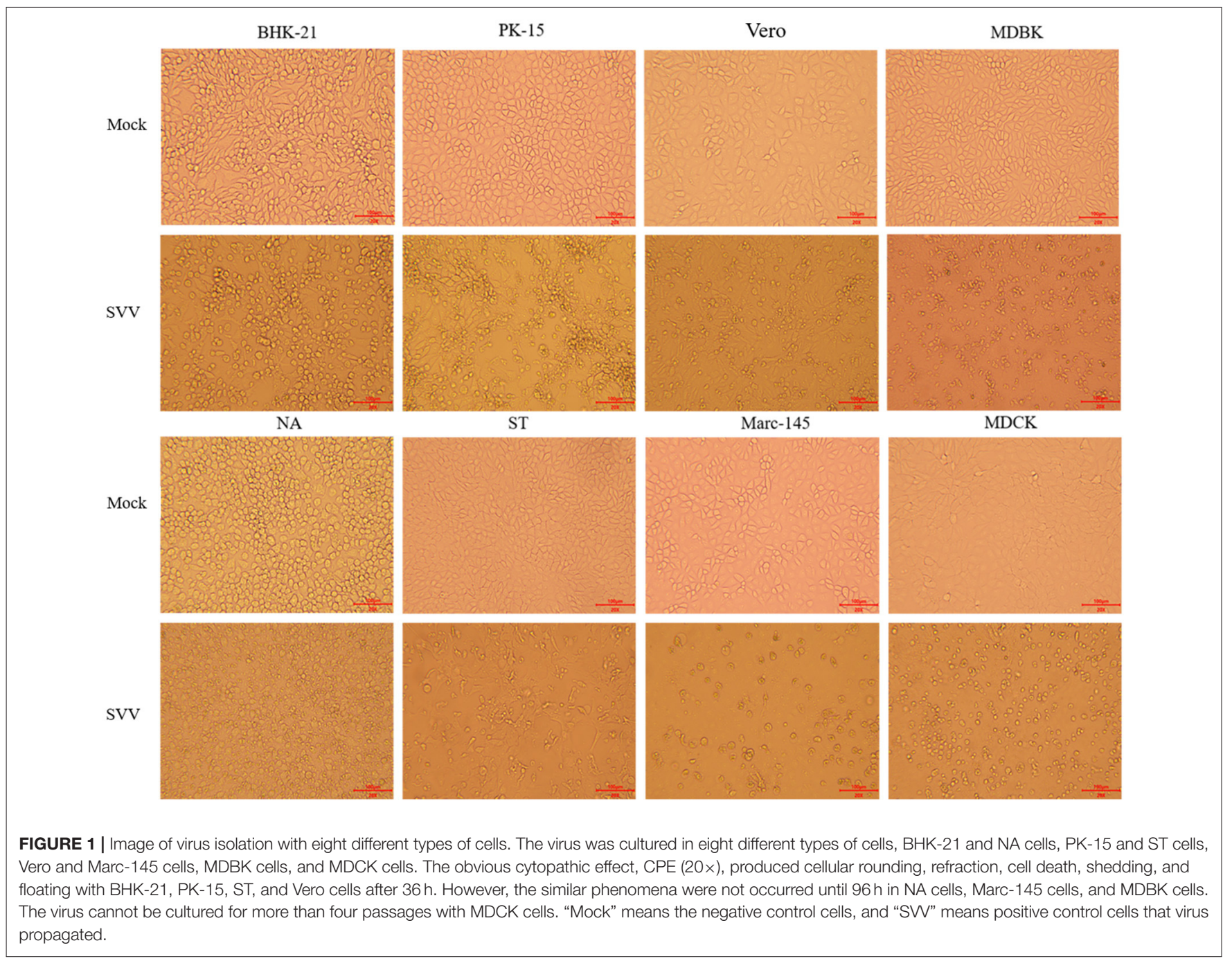


TABLE 2 | Partial nucleotide and amino acid percentage identities of the SVA/GD/China/2018 strain compared with other SW strains.

\begin{tabular}{|c|c|c|c|c|c|}
\hline Country & Area & Strain & $\begin{array}{l}\text { GenBank } \\
\text { number }\end{array}$ & $\begin{array}{c}\text { Nucleotide } \\
\text { similarity }\end{array}$ & $\begin{array}{c}\text { Polyprotein } \\
\text { similarity }\end{array}$ \\
\hline \multirow[t]{15}{*}{ China } & Guangdong & $\begin{array}{l}\text { CH-GDYD- } \\
2017\end{array}$ & MG428683 & $97.3 \%$ & $98.8 \%$ \\
\hline & Guangdong & $\begin{array}{l}\text { CH-GDLZ02- } \\
2017\end{array}$ & MG428681 & $97.4 \%$ & $98.8 \%$ \\
\hline & Guangdong & GD06/2017 & MH316117 & $97.6 \%$ & $99.1 \%$ \\
\hline & Guangdong & $\mathrm{CH}-01-2015$ & KT321458 & $96 \%$ & $98.8 \%$ \\
\hline & Guangxi & SVA/GX/CH/2018 & MK039162 & $96.9 \%$ & $98.6 \%$ \\
\hline & Heilongjiang & SVA/HLJ/CHA/2016 & KY419132 & $97.9 \%$ & $99.1 \%$ \\
\hline & Sichuan & $\begin{array}{l}\text { Sichuan } \\
\text { HS-01 }\end{array}$ & MH588717 & $99.1 \% *$ & $99.3 \%$ \\
\hline & Sichuan & SW-SC-01 & $\mathrm{MH} 716015$ & $96.4 \%$ & $98.5 \%$ \\
\hline & Fujian & CH-FJ-2017 & KY747510 & $98.6 \%$ & $99.1 \%$ \\
\hline & Fujian & $\begin{array}{l}\text { SVA } \\
\mathrm{CH} / \mathrm{FuJ} / 2017\end{array}$ & MH490944 & $97.6 \%$ & $99.0 \%$ \\
\hline & Henan & $\begin{array}{l}\text { CH-HNSL- } \\
2017\end{array}$ & KY747512 & $98.6 \%$ & $99.0 \%$ \\
\hline & Henan & HN01-2017 & $\mathrm{MH064433}$ & $97.5 \%$ & $98.8 \%$ \\
\hline & Anhui & $\begin{array}{l}\mathrm{AH} 01-\mathrm{CH}- \\
2016\end{array}$ & MF460448 & $97.8 \%$ & $99.3 \%$ \\
\hline & Hebei & HB01-2017 & MF967574 & $97.6 \%$ & $98.9 \%$ \\
\hline & Hebei & HB-CH-2016 & KX377924 & $96 \%$ & $98.7 \%$ \\
\hline \multirow[t]{2}{*}{ USA } & Kansas & KS15-01 & KX019804 & $98.5 \%$ & $99.4 \% *$ \\
\hline & lowa & $\begin{array}{l}\text { USA/IA44662/2015 } \\
\text { P1 }\end{array}$ & KU954089 & $98.4 \%$ & $99.4 \% *$ \\
\hline
\end{tabular}

*Indicates maximum.

China and other countries were performed by MegAlign software (DNAStar Lasergene.v7.1) using Clustal W.

\section{RESULTS}

\section{SVV Detection, Isolation, and Propagation}

SVV was detected in two of three samples using RTPCR, and one of two positive oral swabs was used for genome amplification and sequencing. The buffalo-origin SVV was named SVA/GD/China/2018 (GenBank Accession No. MN615881). The virus was purified and propagated stably to 30 passages in BHK-21 cells, NA cells, PK-15 cells, ST cells, Vero cells, Marc- 145 cells, and MDBK cells, but it was propagated only to four passages in MDCK cells in which the SVV cannot be detected after four passages (Figure 1).

\section{Characterization and Sequence Analysis of Buffalo-Origin SVV}

The genome of SVA/GD/China/2018 consists of 7,276 nucleotides. The sequence analysis showed that the genome similarity of SVA/GD/China/2018 was 93.4-99.1\% and the polyprotein similarity was $97.5-99.4 \%$ compared with the other 35 known SVV strains (Table 2). Interestingly, SVA/GD/China/2018 shared the highest nucleotide similarity (99.1\%) with the wild boar strain (Sichuan HS-01) and the highest polyprotein similarity (99.4\%) with the KS15-01 strain.
Genetic evolutionary analysis revealed that SVA/GD/China/2018 clustered in the same branch with Sichuan HS-01 from Sichuan, China (Figure 2).

Compared with the published SVV sequences (Figure 3), SVA/GD/China/2018 was found to have seven unique amino acid substitutions (Figure 2) as follows: 440A (alanine)-V (valine), 497E (glutamic acid) - K (lysine), and 511A (alanine) - V (valine) at the VP3 protein; $1119 \mathrm{~V}$ (valine) $-\mathrm{I}$ (isoleucine) at the $2 \mathrm{C}$ protein; $1430 \mathrm{~A}$ (alanine) $-\mathrm{V}$ (valine) at the $3 \mathrm{~A}$ protein; $1710 \mathrm{H}$ (histidine) $-\mathrm{Y}$ (tyrosine) at the $3 \mathrm{C}$ protein; and $1854 \mathrm{~V}$ (valine)-I (isoleucine) at the $3 \mathrm{D}$ protein.

\section{DISCUSSION}

Viruses such as FMDV (9) and BTV (10), causing symptoms such as ulcers in the mouth and hoof nails, are prevalent in cattle. The results showed that FMDV, BVDV, BTV, VSV, and BoHV-1 were negative, but SVV was detected. This finding was not predicted. Thus, surveillance of SVV in cattle is urgently needed along with animal regression tests.

In order to study the host tropism nature of the virus at the cellular level, eight types of cell lines from four different origins were used to isolate virus from the one of two positive oral swabs. The virus was then successfully purified and cultured to over 30 generations stably in BHK-21 and NA cells of mouse origin, PK-15 and ST cells of pig origin, Vero and 


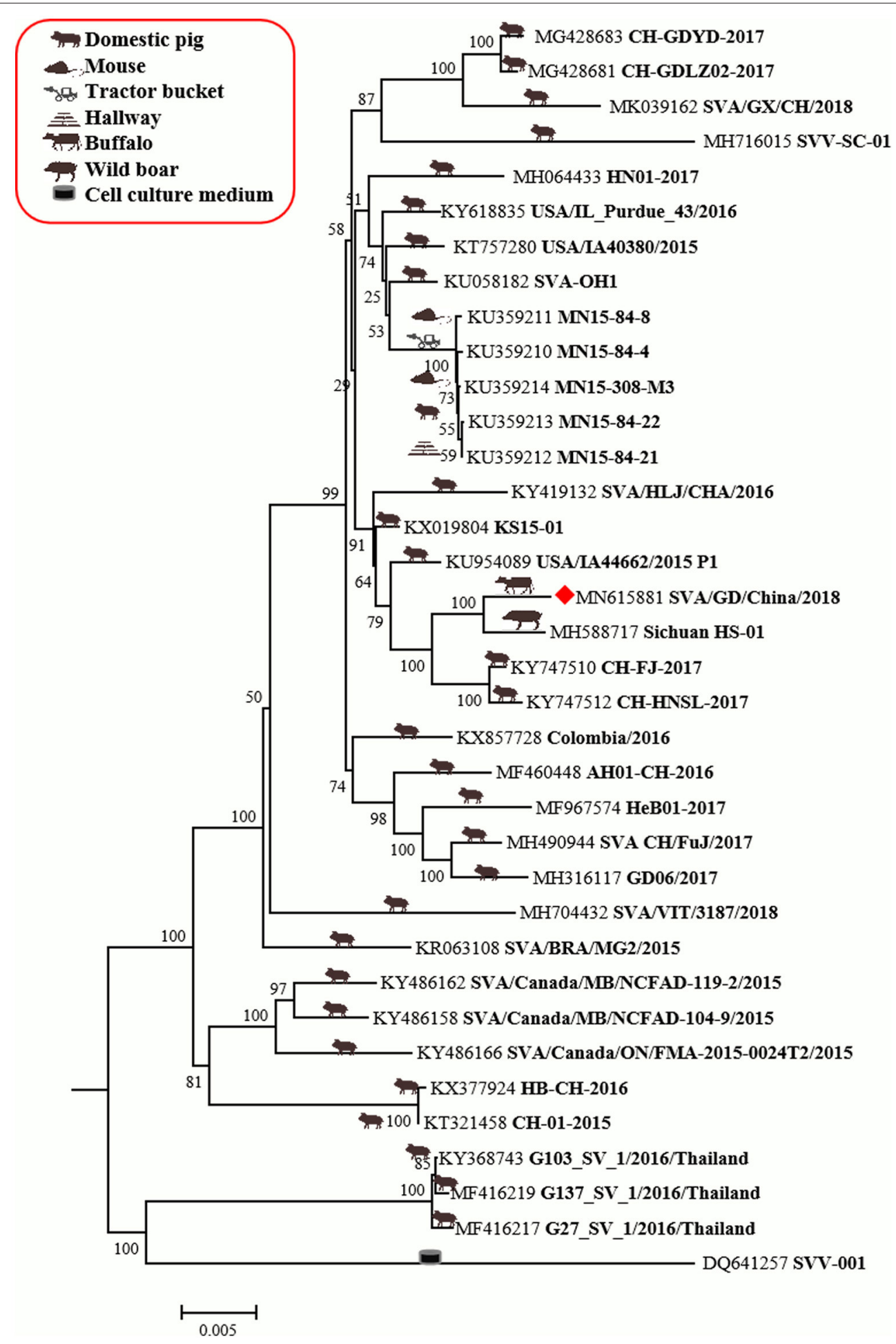

FIGURE 2 | The phylogenetic analysis of SW based on polyprotein nucleotides. Neighbor-joining tree generated with 1,000 bootstrap samplings (MEGA 6.06). The diamond shape represents the strain in this study. The icon before the accession number indicates the host source of the sequence. At present, only SVA/GD/China/2018 has been derived from diseased buffalo and is in the same branch and closely related to the wild boar-origin strain, Sichuan HS-01.

Marc-145 cells of monkey origin, and MDBK cells of bovine origin. However, it could be cultured to only four generations in MDCK cells of dog origin, which indicated that MDCK was not the sensitive cell line for SVV. Alternatively, some special measures are needed such as adding trypsin (11). The typical cytopathic effect (CPE), including rounding of cells, refraction, 


\begin{tabular}{|c|c|c|c|c|c|c|c|c|c|c|c|}
\hline Protein & VP2 & VP3 & VP3 & VP3 & VP3 & VP1 & $2 \mathrm{C}$ & $3 \mathrm{~A}$ & $3 \mathrm{C}$ & $3 \mathrm{D}$ & $3 \mathrm{D}$ \\
\hline \multirow[t]{2}{*}{ Majority } & 'ENGLRNRFTT' & PTAPREN: & MAFGRVSEPEPAS & AVPAQFDI & SYSPPNGAQ1 & KSTAVKHVAVY' & ISPVLQYQ: & LA.PDA.DP' & LKHLG] & DEANGTVDP & LKRKFVQNNDGI \\
\hline & 420 & 440 & $\begin{array}{ll}1 & 1 \\
490 & 500\end{array}$ & 510 & 570 & 910 & 1120 & 1430 & 1710 & 1850 & 2110 \\
\hline DQ641257. & $\frac{\partial \ldots \text {... }}{\ldots \ldots \text {. }}$ & $\overline{\ldots \ldots}$ & ….P.V... & $\frac{1}{\ldots \text { T. } \ldots}$ & $\overline{\ldots \ldots . \mathrm{T} .}$ &,$\ldots \ldots \ldots \ldots$ & $\frac{1}{\ldots \ldots \ldots}$ & $\frac{1}{\text {.T.E... }}$ & $\overline{\ldots \ldots}$ & $\frac{1}{\ldots V \ldots A . \ldots .}$ & $\overline{\ldots \ldots \ldots \ldots}$ \\
\hline MF 416217. & $\ldots \ldots$. & $\ldots \ldots$ & $\ldots \ldots \ldots \ldots \ldots$ & $\ldots$.... & ...... & $\ldots \ldots \ldots$ & $\ldots \ldots$ & ..E... & $\ldots \ldots$ & $\ldots V \ldots$ A. & ..R....... \\
\hline MF416219. & ..... & $\ldots \ldots$ & $\ldots \ldots \ldots \ldots \ldots$ & $\ldots$.... & ...... & $\ldots \ldots \ldots \ldots$ & $\ldots \ldots$ & ..E... & $\ldots \ldots$ & $\ldots V \ldots A$ A. & $\ldots R \ldots \ldots$ \\
\hline KY 368743. & ..... & $\ldots \ldots$ & $\ldots \ldots \ldots \ldots \ldots$ & $\ldots$. . . & ..... & $\ldots \ldots \ldots$ & $\ldots \ldots$ & ..E... & $\ldots \ldots$ & $\ldots V \ldots A$. & ..R....... \\
\hline KY486158. & ....... & $\ldots \ldots$ & $\ldots \ldots \ldots \ldots$ & $\ldots \ldots \ldots$ & ..... &,$G \ldots \ldots \ldots$ & $\ldots \ldots$ & ..E... & $\ldots \ldots$ & $\ldots \ldots$ A. & $\ldots \ldots \ldots \ldots$ \\
\hline KY486162. & ...... & $\ldots \ldots$ & $\ldots \ldots \ldots \ldots$ & $\ldots \ldots \ldots$ & ..... &,.$G \ldots \ldots \ldots$ & $\ldots \ldots$ & ..Е... & $\ldots \ldots$ & $\ldots \ldots$ A. & $\ldots \ldots \ldots \ldots$ \\
\hline KY486166. & .... & $\ldots \ldots$ & $\ldots \ldots$. $\ldots \ldots$ & $\ldots \ldots \ldots$ & ...... &,.$G \ldots \ldots \ldots$ & $\ldots \ldots$ & ..E... & $\ldots \ldots$ & $\ldots \ldots$ A. & $\ldots \ldots \ldots \ldots$ \\
\hline KX377924. & .....YK. & $\ldots \ldots$ & $\ldots \ldots$. $\ldots \ldots$ & $\ldots$. . . & ...... & $\ldots \ldots \ldots \ldots$ & $\ldots \ldots$ & $\ldots \mathrm{QE} \ldots$ & $\ldots \ldots$ & $\ldots V \ldots A$ & $\ldots \ldots \ldots \ldots$ \\
\hline KT321458. & ...... & $\ldots \ldots$ & ..... & $\ldots$.... & ...... & $\ldots \ldots \ldots \ldots$ & $\ldots \ldots$ & . QE . . & $\ldots \ldots$ & $\ldots \mathrm{V} \ldots \mathrm{A}$ & $\ldots \ldots \ldots \ldots$ \\
\hline KR063108. & $\ldots \ldots \ldots$ & $\ldots \ldots$ & $\ldots \ldots \ldots m$ & $\ldots \ldots \ldots$ & $\ldots \ldots \ldots$ & $\ldots$ А...... & $\ldots \ldots$ & $\ldots \ldots$ & $\ldots \ldots$ & $\ldots \ldots \ldots$ & $\ldots \ldots \ldots \ldots$ \\
\hline KU359210. & $\ldots \ldots \ldots$ & $\ldots \ldots$ & ........... & $\ldots \ldots$ & $\ldots \ldots \ldots$ &,$\ldots \ldots \ldots \ldots$ & $\ldots \ldots$ & $\ldots \ldots$ & $\ldots \ldots$ & $\ldots \ldots \ldots$ & $\ldots \ldots \ldots \ldots$ \\
\hline KU359211. & $\ldots \ldots \ldots$ & $\ldots \ldots$ & $\ldots \ldots$ A...... & $\ldots \ldots \ldots$ & $\ldots \ldots \ldots$ &,$\ldots \ldots \ldots \ldots$ & $\ldots \ldots$ & $\ldots \ldots$ & $\ldots \ldots$ & $\ldots \ldots \ldots$ & $\ldots \ldots \ldots \ldots$ \\
\hline KU359212. & $\ldots \ldots \ldots$ & $\ldots \ldots$ & …А..... & $\ldots \ldots \ldots$ & $\ldots \ldots \ldots$ &,$\ldots \ldots \ldots \ldots$ & $\ldots \ldots$ & $\ldots \ldots$ & $\ldots \ldots$ & $\ldots \ldots \ldots$ & $\ldots \ldots \ldots \ldots$ \\
\hline KU359213. & $\ldots \ldots \ldots$ & $\ldots \ldots$ & ‥АА. & $\ldots \ldots \ldots$ & $\ldots \ldots \ldots$ & $\ldots \ldots \ldots \ldots$ & $\ldots \ldots$ & $\ldots \ldots$ & $\ldots \ldots$ & $\ldots \ldots \ldots$ & $\ldots \ldots \ldots \ldots$ \\
\hline KU359214. & $\ldots \ldots \ldots$ & $\ldots \ldots$ & ‥А. А. & $\ldots \ldots$ & $\ldots \ldots \ldots$ & $\ldots \ldots \ldots \ldots$ & $\ldots \ldots$ & $\ldots \ldots$ & $\cdots \cdots$ & $\ldots \ldots \ldots$ & $\cdots \cdots \cdots \cdots$ \\
\hline KU058182. & $\ldots \ldots \ldots$ & $\ldots \ldots$ & $\ldots \ldots m \cdots$ & $\ldots \ldots$ & $\ldots \ldots \ldots$ &,$\ldots \ldots \ldots \ldots$ & $\ldots \ldots$ & $\ldots \ldots$ & $\ldots \ldots$ & $\ldots \ldots \ldots$ & $\ldots \ldots$ \\
\hline KY618835. & $\ldots \ldots \ldots$ & $\ldots \ldots$ & $\ldots \ldots \ldots m \cdots$ & $\ldots \ldots$ & $\ldots \ldots \ldots$ &,$\ldots \ldots \ldots \ldots$ & $\ldots \ldots$ & . T.... & $\ldots \ldots$ & $\ldots \ldots \ldots$ & $\ldots \ldots \ldots$ \\
\hline KT757280. & $\ldots \ldots \ldots$ & $\ldots \ldots$ & $\ldots \ldots \ldots \ldots$ & $\ldots \ldots \ldots$ & $\ldots \ldots \ldots$ &,$\ldots \ldots \ldots$ & $\ldots \ldots$ & $\ldots \ldots$ & $\ldots \ldots$ & $\ldots \ldots \ldots$ & $\ldots \ldots \ldots$ \\
\hline MH064433. & $\ldots \ldots \ldots$ & $\ldots \ldots$ & $\ldots \ldots \ldots \ldots$ & $\ldots \ldots$ & ......... &,$\ldots \ldots \ldots$ & $\ldots \ldots$ & $\ldots \ldots$ & $\ldots \ldots$ & $\ldots \ldots \ldots$ & $\cdots \cdots$ \\
\hline KX019804. & $\ldots \ldots \ldots$ & $\ldots \ldots$ & $\ldots$. & $\ldots \ldots$ & $\ldots \ldots \ldots$ &,$\ldots \ldots \ldots$ & $\ldots \ldots$ & $\ldots \ldots$ & $\ldots \ldots$ & $\ldots \ldots \ldots$ & $\cdots \cdots$ \\
\hline KY419132. & $\ldots \ldots \ldots$ & $\ldots \ldots$ & $\ldots \ldots \ldots \ldots \ldots$ & $\ldots \ldots \ldots$ & $\ldots \ldots \ldots$ &,$\ldots \ldots \ldots \ldots$ & $\ldots \ldots$ & $\ldots \ldots$ & $\ldots \ldots$ & $\cdots \cdots \cdots$ & $\cdots \cdots \cdots \cdots$ \\
\hline KU954089. & $\ldots \ldots \ldots$ & $\ldots \ldots$ & $\ldots \ldots$ А..... & $\ldots \ldots \ldots$ & $\ldots \ldots \ldots$ &,$\ldots \ldots \ldots \ldots$ & $\ldots \ldots \ldots$ & $\ldots \ldots$ & $\ldots \ldots$ & ......... & $\ldots \ldots \ldots \ldots$ \\
\hline MN615881. & $\ldots \ldots \ldots k$ & $\ldots V \mid \ldots$ & $\ldots \ldots \ldots \ldots|\bar{K}| \ldots$ & $\ldots$ v.... & $\ldots \ldots$ T. &,$\ldots$ A..... & $\ldots|\mathrm{I}| \ldots$ & ... $|\mathrm{v}|$. & \begin{tabular}{l|l}
$\ldots \mid$ & $\ldots$ \\
\end{tabular} & $\ldots \ldots$ I] $\ldots$ & $\ldots$.R........ \\
\hline MH588717. & $\ldots \ldots \ldots k$ & $\ldots \ldots$ & $\ldots \ldots \ldots \ldots \ldots$ & $\ldots \ldots \ldots$ & $\ldots \ldots \ldots$ &,$\ldots \ldots \ldots \ldots$ & $\ldots \ldots$ & $\ldots \ldots$ & $\ldots \ldots$ & $\ldots v \ldots . . .$. & $\ldots$ R........ \\
\hline KY747510. & $\ldots \ldots \ldots$ & $\ldots \ldots$ & $\ldots \ldots \ldots \ldots \ldots$ & $\cdots \cdots$ & $\ldots \ldots \ldots$ &,$G \ldots \ldots \ldots$ & $\ldots \ldots$ & $\ldots \ldots$ & $\ldots \ldots$ & $\ldots \ldots \ldots$ & $\cdots \cdots \cdots \cdots$ \\
\hline KY747512. & $\ldots \ldots \ldots$ & $\ldots \ldots$ & $\ldots \ldots \ldots \ldots \ldots$ & $\ldots \ldots \ldots$ & $\ldots \ldots \ldots \ldots$ &,.$G \ldots \ldots \ldots$ & $\ldots \ldots \ldots$ & $\ldots \ldots$ & $\ldots \ldots$ & $\ldots \ldots \ldots$ & $\ldots \ldots \ldots \ldots$ \\
\hline KX857728. & $\ldots \ldots \ldots$ & $\ldots \ldots$ & $\ldots \ldots \ldots \ldots \ldots$ & $\ldots \ldots$ & $\ldots \ldots \ldots$ &,$\ldots \ldots \ldots \ldots$ & $\ldots \ldots$ & $\ldots \ldots$ & $\ldots \ldots$ & $\ldots \ldots \ldots$ & $\ldots \ldots \ldots \ldots$ \\
\hline MF 460448 . & $\ldots \ldots \ldots$ & $\ldots \ldots$ & $\ldots \ldots \ldots \ldots \ldots$ & $\ldots \ldots$ & ...... &,$\ldots \ldots \ldots$ & $\ldots \ldots$ & $\ldots \ldots$ & $\ldots \ldots$ & $\ldots \ldots \ldots$ & $\ldots \ldots$ \\
\hline MF967574. & .s...... & $\ldots \ldots$ & $\ldots \ldots \ldots \ldots \ldots$ & $\ldots \ldots$ & $\ldots \ldots \ldots$ & $\ldots \ldots \ldots$ & $\ldots \ldots$ & $\ldots \ldots$ & .N. . & $\ldots \ldots$ & $\ldots \ldots$. \\
\hline MH490944. & $\ldots \ldots \ldots$ & $\ldots \ldots$ & $\ldots \ldots \ldots \ldots$ & $\ldots \ldots$ & $\ldots \ldots \ldots$ & $\ldots \ldots \ldots \ldots$ & $\ldots \ldots$ & $\ldots \ldots$ & $\ldots \ldots$ & $\ldots \ldots \ldots$ & $\cdots \cdots \cdots \cdots$ \\
\hline MH316117. & $\ldots \ldots \ldots$ & $\ldots \ldots$ & $\cdots \cdots \cdots \cdots$ & $\ldots \ldots \ldots$ & $\ldots \ldots \ldots$ &,$\ldots \ldots \ldots$ & $\ldots \ldots$ & $\ldots \ldots$ & $\ldots \ldots$ & $\ldots \ldots \ldots$ & $\ldots \ldots \ldots \ldots$ \\
\hline MG428681. & $\ldots \ldots \ldots$ & $\ldots \ldots$ & $\ldots \ldots \ldots \cdots \cdots$ & $\ldots \ldots \ldots$ & $\ldots$ &,$\ldots \ldots \ldots \ldots$ & $\ldots \ldots$ & $\ldots \ldots$ & . R... & $E \ldots \ldots \ldots$ & $\ldots \ldots \ldots \ldots$ \\
\hline MG428683. & $\ldots \ldots \ldots$ & $\ldots \ldots$ & $\ldots \ldots \ldots \ldots \ldots$ & $\ldots \ldots \ldots$ & $\ldots$ & $\ldots \ldots \ldots \ldots$ & $\ldots \ldots$ & $\ldots \ldots$ & .R... & E...... & $\ldots \ldots \ldots \ldots$ \\
\hline MK039162. & $\ldots \ldots \ldots$ & $\ldots \ldots$ & $\ldots \ldots \ldots \ldots \ldots$ & $\ldots \ldots$ & $\ldots$ & $\ldots \ldots \ldots$ & $\ldots \ldots$ & $\ldots \ldots$ & . R... & $\ldots \ldots \ldots$ & . \\
\hline MH716015. & $\ldots \ldots \ldots$ & $\ldots \ldots$ & $\ldots \ldots \ldots \ldots \ldots$ & $\ldots \ldots$ & $\ldots \ldots \ldots$ & $\ldots \ldots \ldots$ & $\ldots \ldots$ & $\ldots \ldots$ & $\ldots \ldots$ & $\ldots \ldots \ldots$ & $\ldots \ldots \ldots \ldots$ \\
\hline MH704432. & $\ldots \ldots \ldots$ & $\ldots \ldots$ & $\ldots \ldots \ldots \ldots \ldots$ & $\ldots \ldots \ldots$ & …... &,.$G I \ldots \ldots \ldots$ & $\ldots \ldots \ldots$ & $\ldots$ & $\ldots \ldots$ & $\ldots s \ldots \ldots$ & n.w. \\
\hline
\end{tabular}

FIGURE 3 | Amino acid sequence alignment of the polyproteins. The SVA/GD/China/2018 strain had seven different amino acids, including 440A (alanine) - V (valine), 497E (glutamic acid) - K (lysine), 511A (alanine) - V (valine) at the VP3 protein; 1119V (valine) - I (isoleucine) at the 2C protein; 1430A (alanine) - V (valine) at the 3A protein; $1710 \mathrm{H}$ (histidine) $-\mathrm{Y}$ (tyrosine) at the 3C protein, $1854 \mathrm{~V}$ (valine) - I (Isoleucine) at the 3D protein. For mutations pertaining to amino acids at position $427 \mathrm{~K}$ (lysine, VP2 protein), 2104R (arginine, 3D protein) was the same as the first wild boar strain, Sichuan HS-01, in China. The "red frame" indicates the buffalo-origin Seneca Valley virus sequence we isolated, and the "blue frame" indicates the different amino acids compared with other sequences.

cell death, shedding, and floating, were observed on BHK-21, PK-15, ST, and Vero cells after $36 \mathrm{~h}$, but there was no CPE on another four cells until $96 \mathrm{~h}$ (Figure 1). These phenomena indicated that rats, cattle, and monkeys might also be the host of SVV (8), but not dogs. According to previous studies, SVV is pathogenic and causes clinical symptoms in pigs, but it is unclear whether SVV infection could result in visible clinical symptoms in cattle (12). Whether the species supporting replication of SVV in their related cell lines are competent hosts for the virus still needs further confirmation. More studies on related primary cell lines need to be done, such as swine acute diarrhea syndrome coronavirus (SADS-CoV), avian influenza virus, and severe acute respiratory syndrome coronavirus 2 (SARS-CoV2) (13-15).

The genome of SVA/GD/China/2018 shared lower nucleotide similarity (96-97.6\%) and polyprotein similarity (98.8-99.1\%) compared with those strains from Guangdong and near Guangdong (Table 2). Interestingly, it shared the highest nucleotide similarity with a wild boar-origin strain (Sichuan
HS-01) and the highest polyprotein similarity with the KS1501 strain, which indicated that SVA/GD/China/2018 was a mutant strain (16). To date, the majority of studies on the genetic relationship analysis of SVV were based on its nucleotide sequence (17-19), while some studies were based on amino acid sequence (20) or on the nucleotide sequence and amino acid sequence simultaneously (21). Because this is the first time to report SVV in buffalo, it is particularly important to investigate and analyze the origin and variation of the virus strain in detail. Therefore, we used both nucleotide sequence and amino acid sequence data of SVV for genetic evolution analysis. Our results showed that the constructed genetic evolutionary tree based on the nucleotide sequence and amino acid sequence of the virus showed a completely consistent trend: SVA/GD/China/2018 is located in the same branch as Sichuan HS-01 from Sichuan, China, indicating that the potential buffalo-derived strain originated from swine. However, the distance between Guangdong and Sichuan is more than 2,000 km long; therefore, 
further analysis and investigation about how it was transmitted are required.

Interestingly, excluding the possibility of the primers used for amplification to introduce changes in the amplicons, SVA/GD/China/2018 shared the same different amino acids at both $427 \mathrm{~K}$ (lysine, VP2 protein) and 2104R (arginine, 3D protein) positions, as the first wild boar strain, Sichuan HS-01 (GenBank Accession No. MH588717), in China. In contrast to other porcine strains, they have only one or two mutations. This finding reveals that the virus may have undergone adaptive changes in different hosts (20); however, further investigation is required to elucidate the role of these two residues. VP1 contains a hypervariable region with at least two antigenic sites located at both amino acid 140-160 and amino acid 200-213 sites (22). It has been reported that $228 \mathrm{~K}$ in VP1, 141-143LDV, and 143-148DGK in VP2 are the primary antigenic sites of FMDV (23). None of these three motifs and antigenic sites of the SVA/GD/China/2018 strain have changed, indicating similar antigenicity and biological characteristics of this strain compared to others (24). The majority of the characteristics are unique, because the different amino acids were located in the VP3 protein. However, further study is required to investigate the effect of these changes.

In summary, we isolated a buffalo-origin SVV strain for the first time and cultured the virus in seven cell lines of different animal origins, and genetic evolution studies revealed the possibility of cross-species transmission of SVV (25).

\section{DATA AVAILABILITY STATEMENT}

The datasets presented in this study can be found in online repositories. The names of the repository/repositories and accession number(s) can be found below: https://www.ncbi.nlm. nih.gov/genbank/, MN615881.

\section{REFERENCES}

1. Venkataraman S, Reddy SP, Loo J, Idamakanti N, Hallenbeck PL, Reddy VS. Structure of Seneca Valley Virus-001, an oncolytic picornavirus representing a new genus. Structure. (2008) 16:1555-61. doi: 10.1016/j.str.2008.07.013

2. Leme RA, Oliveira TES, Alcântara BK, Headley SA, Alfieri AF, Yang M, et al. Clinical manifestations of senecavirus a infection in neonatal pigs, Brazil, 2015. Emerg Infect Dis. (2016) 22:1238-41. doi: 10.3201/eid2207.151583

3. Vannucci FA, Linhares DCL, Barcellos DESN, Lam HC, Collins J, Marthaler D. Identification and complete genome of Seneca Valley Virus in vesicular fluid and sera of pigs affected with idiopathic vesicular disease, Brazil. Transbound Emerg Dis. (2015) 62:589-93. doi: 10.1111/tbed.12410

4. Wang L, Prarat M, Hayes J, Zhang Y. Detection and genomic characterization of Senecavirus A, Ohio, USA, 2015. Emerg Infect Dis. (2016) 22:13213. doi: 10.3201/eid2207.151897

5. Liu J, Zha Y, Li H, Sun Y, Wang F, Lu R, et al. Novel recombinant Seneca Valley Virus isolated from slaughtered pigs in Guangdong Province. Virol Sin. (2019) 34:722-4. doi: 10.1007/s12250-019-00139-8

6. Joshi LR, Mohr KA, Clement T, Hain KS, Myers B, Yaros J, et al. Detection of the emerging Picornavirus Senecavirus A in pigs, mice, and houseflies. J Clin Microbiol. (2016) 54:1536-45. doi: 10.1128/JCM.03390-15

7. Claus MP, Alfieri AF, Folgueras-Flatschart ÁV, Wosiacki SR, Médici KC, Alfieri AA. Rapid detection and differentiation of bovine herpesvirus 1 and 5

\section{ETHICS STATEMENT}

Ethical review and approval were not required for the study because the samples used in the present study were taken from field animals by veterinarians. The samples were taken and submitted to Institute of Animal Health, Guangdong Academy of Agricultural Sciences.

\section{AUTHOR CONTRIBUTIONS}

$\mathrm{XZ}$ and $\mathrm{W}$-FL carried out conceptual and experimental work and wrote the first draft of the manuscript. G-BS, J-HL, Z-FC, and $\mathrm{W}-\mathrm{YC}$ contributed to the writing and review of the manuscript. D-HL, X-HW, QZ, S-LZ, ML, and D-SH supervised. All authors have approved this manuscript for publication.

\section{FUNDING}

This study was mostly supported by a grant (Grant No. 2019B020217002) from the Guangdong Provincial Department of Science and Technology, and two grants (Disciplinary Team Construction Program, Grant No. 202122TD and Jinying's Star Talent Program, Grant No. R2018PY-JX003) from Guangdong Academy of Agricultural Sciences, a grant (Grant No. 201906040005) from Guangzhou Science and Technology Bureau, and two grants (Grant Nos. 2021KJ114 and 2021KJ119) from Guangdong Provincial Department of Agriculture and Rural Affairs. Moreover, this study was also partly supported by the Maoming Branch and Zhaoqing Branch, Guangdong Laboratory for Lingnan Modern Agriculture, and Scientific Observation and Experiment Station of Veterinary Drugs and Diagnostic Techniques of Guangdong Province, Ministry of Agriculture of Rural Affairs, and Key Laboratory of Animal Disease Prevention of Guangdong Province.

glycoprotein C gene in clinical specimens by multiplex-PCR. J Virol Methods. (2005) 128:183-8. doi: 10.1016/j.jviromet.2005.05.001

8. Chen L, Zhang J, Wang M, Pan S, Mou C, Chen Z. Pathogenicity of two Chinese Seneca Valley virus. (SVV) strains in mice and pigs. Microb Pathog. (2019) 136:103695. doi: 10.1016/j.micpath.2019.103695

9. Peng J, Yi J, Yang W, Ren J, Wen Y, Zheng H, et al. Advances in footand-mouth disease virus proteins regulating host innate immunity. Front Microbiol. (2020) 11:2046. doi: 10.3389/fmicb.2020.02046

10. Haegeman A, Vandaele L, De Leeuw I, Oliveira AP, Nauwynck H, Van Soom A, et al. Failure to remove Bluetongue Serotype 8 Virus. (BTV-8) from in vitro produced and in vivo derived bovine embryos and subsequent transmission of BTV-8 to recipient cows after embryo transfer. Front Vet Sci. (2019) 6:432. doi: 10.3389/fvets.2019.00432

11. Kong F, Niu X, Liu M, Wang Q. Bile acids LCA and CDCA inhibited porcine deltacoronavirus replication in vitro. Vet Microbiol. (2021) 257:109097. doi: 10.1016/j.vetmic.2021.109097

12. Zhang S, Cao Y, Yang Q. Transferrin receptor 1 levels at the cell surface influence the susceptibility of newborn piglets to PEDV infection. PLoS Pathog. (2020) 16:e1008682. doi: 10.1371/journal.ppat.1008682

13. Edwards CE, Yount BL, Graham RL, Leist SR, Hou YJ, Dinnon KH, et al. Swine acute diarrhea syndrome coronavirus replication in primary human cells reveals potential susceptibility to infection. Proc Natl Acad Sci USA. (2020) 117:26915-25. doi: 10.1073/pnas.2001046117 
14. Ruiz-Hernandez R, Mwangi W, Peroval M, Sadeyen JR, Ascough S, Balkissoon $\mathrm{D}$, et al. Host genetics determine susceptibility to avian influenza infection and transmission dynamics. Sci Rep. (2016) 6:26787. doi: 10.1038/srep26787

15. Zhu Y, Feng F, Hu G, Wang Y, Yu Y, Zhu Y, et al. A genome-wide CRISPR screen identifies host factors that regulate SARS-CoV-2 entry. Nat Commun. (2021) 12:961. doi: 10.1038/s41467-021-21213-4

16. Wang M, Chen L, Pan S, Mou C, Shi K, Chen Z. Molecular evolution and characterization of novel Seneca Valley virus. (SVV) strains in South China. Infect Genet Evol. (2019) 69:1-7. doi: 10.1016/j.meegid.2019.01.004

17. Wang H, Niu C, Nong Z, Quan D, Chen Y, Kang O, et al. Emergence and phylogenetic analysis of a novel Seneca Valley virus strain in the Guangxi Province of China. Res Vet Sci. (2020) 130:207-11. doi: 10.1016/j.rvsc.2020.03.020

18. Leme RA, Zotti E, Alcântara BK, Oliveira MV, Freitas LA, Alfieri AF, et al. Senecavirus A: an emerging vesicular infection in Brazilian pig herds. Transbound Emerg Dis. (2015) 62:603-11. doi: 10.1111/tbed.12430

19. Saeng-chuto K, Stott CJ, Wegner M, Kaewprommal P, Piriyapongsa J, Nilubol D. The full-length genome characterization, genetic diversity and evolutionary analyses of Senecavirus A isolated in Thailand in 2016. Infect Genet Evol. (2018) 64:32-45. doi: 10.1016/j.meegid.2018.06.011

20. Xu W, Hole K, Goolia M, Pickering B, Salo T, Lung O, et al. Genome wide analysis of the evolution of Senecavirus A from swine clinical material and assembly yard environmental samples. PLoS ONE. (2017) 12:e0176964. doi: 10.1371/journal.pone.0176964

21. Qian S, Fan W, Qian P, Chen H, Li X. Isolation and full-genome sequencing of Seneca Valley virus in piglets from China, 2016. Virol J. (2016) 13:173. doi: 10.1186/s12985-016-0631-2

22. Saeng-chuto K, Rodtian P, Temeeyasen G, Wegner M, Nilubol D. The first detection of Senecavirus A in pigs in Thailand, 2016. Transbound Emerg Dis. (2018) 65:285-8. doi: 10.1111/tbed.12654
23. Bai X, Bao H, Li P, Wei W, Zhang M, Sun P, et al. Effects of two amino acid substitutions in the capsid proteins on the interaction of two celladapted PanAsia-1 strains of foot-and-mouth disease virus serotype $\mathrm{O}$ with heparan sulfate receptor. Virol J. (2014) 11:132. doi: 10.1186/1743-422X11-132

24. Chen Y, Xu Q, Tan C, Li X, Chi X, Cai B, et al. Genomic analysis of codon usage shows influence of mutation pressure, natural selection, and host features on Senecavirus A evolution. Microb Pathog. (2017) 112:3139. doi: 10.1016/j.micpath.2017.09.040

25. Cui J, Li F, Shi ZL. Origin and evolution of pathogenic coronaviruses. Nat Rev Microbiol. (2019) 17:181-92. doi: 10.1038/s41579-018-0118-9

Conflict of Interest: The authors declare that the research was conducted in the absence of any commercial or financial relationships that could be construed as a potential conflict of interest.

Publisher's Note: All claims expressed in this article are solely those of the authors and do not necessarily represent those of their affiliated organizations, or those of the publisher, the editors and the reviewers. Any product that may be evaluated in this article, or claim that may be made by its manufacturer, is not guaranteed or endorsed by the publisher.

Copyright (C) 2021 Zhou, Liang, Si, Li, Chen, Cai, Lv, Wen, Zhai, Zhai, Liao and He. This is an open-access article distributed under the terms of the Creative Commons Attribution License (CC BY). The use, distribution or reproduction in other forums is permitted, provided the original author(s) and the copyright owner(s) are credited and that the original publication in this journal is cited, in accordance with accepted academic practice. No use, distribution or reproduction is permitted which does not comply with these terms. 